\title{
Apresentação do Dossiê
}

Esta edição da Revista Debates oferece um dossiê sobre a "Pesquisa Brasileira de Mídia" (PBM), conjunto formado por dois surveys realizados em 2013 e 2014 pelo Ibope Inteligência sob encomenda da Secretaria de Comunicação Social da Presidência da República. Ambos os estudos e suas bases de dados públicas dão contribuição inédita à construção do conhecimento sobre os hábitos de uso da mídia no Brasil e alguns de seus efeitos sobre a sociedade brasileira.

Diversos conceitos e perguntas utilizados nos questionários da PBM foram inspirados em estudos internacionais como o European Social Survey (ESS) e o Latin American Public Opinion Project (Lapop). Além disso, as duas ondas da pesquisa contaram com a consultoria de reconhecidos pesquisadores da área. $\mathrm{Na}$ edição 2014 da PBM, cuja realização ocorreu em 2013 sob a coordenaçáo do organizador deste dossiê, participaram de reunióes preparatórias Edison Nunes (PUC-SP), Emerson Cervi (UFPR), Leandro Molhano (FGV-RJ), Lúcio Rennó (UnB), Mara Telles (UFMG), Marcelo Simas (IUPERJ), Mathieu Turgeon (UnB), Pedro Mundim (UFG) e Rachel Meneguello (Unicamp). Na edição 2015, cuja realização ocorreu em 2014 sob a coordenação de Pedro Mundim, participaram das discussóes de revisão do questionário Emerson Cervi (UFPR), Mauro Porto (Tulane University), Rogério Christofoletti (UFSC) e o organizador deste dossiê.

Em ambas as ondas, os surveys foram estruturados sobre amostras representativas de cada uma das 27 unidades da federação que, com a aplicaçáo de um fator de ponderação, representam também a população nacional. Em cada ano, 18.312 brasileiros com 16 anos ou mais foram entrevistados. A representatividade na PBM distingue-a inequivocamente de outros estudos de audiência ou hábitos de uso da mídia dirigidos ao mundo do consumo, realizados por organizaçóes do setor privado e que privilegiam amostras representativas de náo mais que duas dezenas de grandes centros urbanos, esquecendo o interior do país e regióes pobres ou escassamente povoadas.

Alguns dos trabalhos publicados neste dossiê foram apresentados e discutidos anteriormente em encontros acadêmicos. Em 2014, o VI Congresso Wapor América Latina (Santiago, Chile) e o IX Encontro da Associação Brasileira de Ciência Política (Brasília, Brasil) acolheram a mesa "Estudo Brasileiro de Mídia - Um panorama descritivo dos hábitos de uso dos meios de comunicação pela populaçáo brasileira". Os autores deste dossiê que puderam participar desses encontros agradecem aos assistentes e comentaristas por críticas e sugestôes.

Nesta edição, cinco artigos do dossiê exploram diferentes tópicos da PBM, ordenados do objeto mais genérico ao mais específico. O primeiro texto, de autoria de Wladimir G. Gramacho e André Jácomo, ocupa-se da descrição dos seis padrôes 
de uso dos meios de comunicação no Brasil e da influência do uso de diferentes repertórios midiáticos sobre o nível de informação política dos brasileiros. A principal conclusão do estudo, baseado na edição 2015 da PBM, é que, no Brasil, repertórios midiáticos que incluem a internet estão associados a maiores níveis de informação política e não o contrário, como apontado em outras pesquisas.

O segundo texto, de Pedro Santos Mundim, ocupa-se da televisão, o meio de comunicação quase universal no Brasil. Mais especificamente, o artigo analisa os hábitos de consumo de notícias e os fatores que determinam a exposição dos brasileiros aos principais telejornais do país. Utilizando dados da PBM 2014, o autor mostra que a grade de programação é um fator importante na explicação do consumo de telejornais no Brasil, especialmente do Jornal Nacional e do Jornal da Record. Mais especificamente, novelas atraem audiência aos telejornais. Outras variáveis também têm influência nessa escolha, como escolaridade, idade, interesse por política e afiliação religiosa.

Prospectando o avanço da nova mídia no país, o terceiro texto, de autoria de Emerson Urizzi Cervi, busca esclarecer para quem a internet é central no Brasil. Também com base em dados de 2014, o artigo propóe um Índice de Centralidade da Internet (ICI). Ao aplicá-lo, o estudo identifica que limitaçóes de renda não são barreiras significativas para o uso da internet entre nós. O fosso digital, segundo o texto, seria explicado por outras características individuais, como a escolaridade e a idade.

Já Eduardo Nunomura combina dados das duas ondas da PBM para analisar diferenças e aproximaçóes dos leitores da imprensa nacional e regional. $\mathrm{O}$ autor observou, por exemplo, que os jovens se informam menos pelos jornais impressos em praças não atendidas por três diários de referência nacional - Folha de $S$. Paulo, $O$ Estado de S. Paulo e O Globo -, sugerindo relativa força desses diários em preservar um número maior de leitores jovens. $\mathrm{O}$ autor também compara o consumo de jornais nacionais e regionais de $2^{\mathrm{a}}$ à $\sigma^{\mathrm{a}}$ feira e nos finais de semana, seu uso por nível de escolaridade e faixa de renda, entre outras variáveis.

Finalmente, o quinto artigo do dossiê explora um tema distinto, a influência da mídia na popularidade do governo federal. Helcimara Telles, Thiago Sampaio e Érica Baptista analisaram dados da PBM 2014 e concluíram que a mídia tem limitada capacidade de influenciar a popularidade governamental, muito melhor explicada pelos principais problemas nacionais identificados pelos entrevistados e por seu nível de escolaridade.

Também estão publicados neste número da Revista Debates dois artigos de temas livres. Fernando Barrientos del Monte apresenta um modelo analítico para 
compreender os tipos de oposição aos governos presentes nas democracias ocidentais, entendendo que sua existência e atuação são vitais para a saúde de sistemas políticos competitivos. Já Marco Iazzetta analisa as condiçóes do surgimento de organizaçóes armadas de esquerda nos anos 1960 e 1970 na Argentina, chamando a atenção para as condiçóes políticas que estiveram na raiz das reaçóes violentas populares e de organizações guerrilheiras.

O organizador:

Wladimir G. Gramacho (Universidade de Brasília/ Brasil) 
